\title{
Perfil fitoquímico e microbiológico do extrato das folhas de Achyrocline satureioides
}

\section{(Lam.) DC. (Macela)}

Phytochemical and microbiological profile of the extract of the leaves of Achyrocline satureioides

(Lam.) DC. (Macela)

Perfil fitoquímico y microbiológico del extracto de hojas de Achyrocline satureioides (Lam.) DC.

(Macela)

Amanda Beatriz Alves

ORCID: https://orcid.org/0000-0002-3336-8958 Universidade José do Rosário Vellano, Brasil

E-mail: alves.amandabeatriz@ outlook.com

Flávio Augusto Oliveira

ORCID: https://orcid.org/0000-0003-3560-0586

Universidade José do Rosário Vellano, Brasil

E-mail: flavioaugustofotografia@gmail.com

Gabrielly Borges de Souza

ORCID: https://orcid.org/0000-0002-0614-2451

Universidade José do Rosário Vellano, Brasil

E-mail: gabiborges9001@ hotmail.com

Laila Helena Machado

ORCID: https://orcid.org/0000-0002-9598-4019

Universidade José do Rosário Vellano, Brasil

E-mail: layla-machado1997@hotmail.com

Sofia de Castro Oliveira

ORCID: https://orcid.org/0000-0002-1863-2079

Universidade José do Rosário Vellano, Brasil

E-mail: sofiadecastrooliveira@ hotmail.com

Michele Carolina Terra

ORCID: https://orcid.org/0000-0003-4139-4256

Universidade José do Rosário Vellano, Brasil

E-mail: michelecaroline_2012@ hotmail.com

Kamila Rotondo

ORCID: https://orcid.org/0000-0002-7808-0755

Universidade José do Rosário Vellano, Brasil

E-mail: kamilaoliveira959@gmail.com

João Paulo Lopes Jordão

ORCID: https://orcid.org/0000-0001-7596-1031

Universidade José do Rosário Vellano, Brasil

E-mail: joao.jordao@aluno.unifenas.br

Guilherme Fantinato

ORCID: https://orcid.org/0000-0002-8968-7093

Universidade José do Rosário Vellano, Brasil

E-mail: guilherme.fantinato1@ hotmail.com

Gabriel Lopes Chaves

ORCID: https://orcid.org/0000-0001-8735-8344

Universidade José do Rosário Vellano, Brasil

E-mail:gabriel.chaves@aluno.unifenas.br

Luciana Rosa Alves Rufino

ORCID: https://orcid.org/0000-0002-8364-9379

Universidade José do Rosário Vellano, Brasil

E-mail: lufeliciano1@hotmail.com

Bruno Cesar Correa Salles

ORCID: https://orcid.org/0000-0002-4444-9673

Universidade José do Rosário Vellano, Brasil

E-mail: bruno.salles@unifenas.br

Gérsika Bitencourt Santos

ORCID: https://orcid.org/ 0000-0003-0849-2786

Universidade José do Rosário Vellano, Brasil

E-mail: gersika.santos@unifenas.br 


\begin{abstract}
Resumo
Objetivo: A Achyrocline satureioides (Lam.) DC. (Macela) é conhecida popularmente por suas propriedades antiinflamatórias, antiespasmódicas e contra desordens intestinais. O presente trabalho teve como objetivo analisar a atividade microbiológica e o perfil fitoquímico do extrato das folhas da Macela caracterizando seus grupos metabólicos secundários e seus constituintes. Métodos: Foi preparado o extrato hidroetanólico da Macela. Para análise microbiológica, as bactérias foram incubadas em ágar sangue e os fungos foram cultivados em ágar Sabouraud Dextrose (ASD - Himediaß). As placas foram incubadas a $37^{\circ} \mathrm{C}$ e após 24 horas utilizou-se o paquímetro digital para verificar o diâmetro formado pelo halo de inibição promovido pelos extratos e controles. O perfil fitoquímico do extrato hidroetanólico da Macela realizou-se através do espectrofotômetro. Pelo método de DDPH foi analisada a capacidade sequestrante de radicais livres do extrato estudado. Resultados: A análise microbiológica mostrou que não houve inativação das cepas dos microrganismos testados. O perfil fitoquímico evidenciou alto teor de compostos fenólicos totais e flavonoides; e a análise do DPPH mostrou uma interessante capacidade antioxidante, mas não similar ao sintético BHT. Conclusão/Considerações finais: $\mathrm{O}$ extrato não apresentou atividade antimicrobiana frente as bactérias e fungos analisados, mas possui grande quantidade de compostos fenólicos e flavonoides e atividade antioxidante.
\end{abstract}

Palavras-chave: Compostos fitoquímicos; Flavonoides; Plantas medicinais.

\begin{abstract}
Objective: Achyrocline satureioides (Lam.) DC. (Macela) is popularly known for its anti-inflammatory, antispasmodic and intestinal disorders. The present work aimed to analyze the microbiological activity and the phytochemical profile of the extract of the leaves of Macela characterizing their secondary metabolic groups and their constituents. Methods: Macela hydroethanolic extract was prepared. For microbiological analysis, the bacteria were incubated on blood agar and the fungi were cultured on Sabouraud Dextrose agar (ASD - Himedia®). The plates were incubated at $37^{\circ} \mathrm{C}$ and after 24 hours the digital caliper was used to check the diameter formed by the inhibition halo promoted by the extracts and controls. The phytochemical profile of the hydroethanolic extract of Macela was carried out through the spectrophotometer. The DDPH method was used to analyze the free radical scavenging capacity of the studied extract. Results: The microbiological analysis showed that there was no inactivation of the strains of the tested microorganisms. The phytochemical profile showed a high content of total phenolic compounds and flavonoids; and the DPPH analysis showed an interesting antioxidant capacity, but not similar to the synthetic BHT. Conclusion / Final considerations: The extract did not show antimicrobial activity against the analyzed bacteria and fungi, but it has a large amount of phenolic and flavonoid compounds and antioxidant activity.
\end{abstract}

Keywords: Phytochemicals; Flavonoids; Medicinal plants.

\title{
Resumen
}

Objetivo: Achyrocline satureioides (Lam.) DC. (Macela) es conocida popularmente por sus trastornos antiinflamatorios, antiespasmódicos e intestinales. El presente trabajo tuvo como objetivo analizar la actividad microbiológica y el perfil fitoquímico del extracto de las hojas de Macela caracterizando sus grupos metabólicos secundarios y sus constituyentes. Métodos: Se preparó extracto hidroetanólico de Macela. Para el análisis microbiológico, las bacterias se incubaron en agar sangre y los hongos se cultivaron en agar Sabouraud Dextrosa (ASD - Himedia ${ }^{\circledR}$ ). Las placas se incubaron a $37^{\circ} \mathrm{C}$ y después de 24 horas se utilizó el calibre digital para comprobar el diámetro formado por el halo de inhibición promovido por los extractos y controles. El perfil fitoquímico del extracto hidroetanólico de Macela se realizó a través del espectrofotómetro. Se utilizó el método DDPH para analizar la capacidad captadora de radicales libres del extracto estudiado. Resultados: El análisis microbiológico mostró que no hubo inactivación de las cepas de los microorganismos probados. El perfil fitoquímico mostró un alto contenido de compuestos fenólicos totales y flavonoides; y el análisis DPPH mostró una interesante capacidad antioxidante, pero no similar al BHT sintético. Conclusión / Consideraciones finales: El extracto no mostró actividad antimicrobiana contra las bacterias y hongos analizados, pero tiene una gran cantidad de compuestos fenólicos y flavonoides y actividad antioxidante.

Palabras clave: Fitoquímicos; Flavonoides; Plantas medicinales.

\section{Introdução}

O uso de extrato de plantas para fins medicinais é uma prática antiga da humanidade e por muito tempo era a única maneira de se tratar as enfermidades ocasionadas por agentes microbianos. Com o passar dos anos os medicamentos foram surgindo e caindo no gosto popular e da área farmacêutica com as principais drogas sendo utilizadas para cura de infecções. Ainda assim, alguns países em desenvolvimento dependem das plantas medicinais como única forma de acesso aos cuidados básicos de saúde (Carvalho, 2018).

A Achyrocline satureioides (Lam.) é conhecida no Brasil popularmente por alecrim-de-parede, camomila-nacional, 
carrapichinho-de-agulha, chá-de-lagoa, losua-do-mato, macela, macela-amarela, macelinha, marcela, marcela-da-terra, marcela-do-campo, macela-do-sertão, marcela-galega, paina, marcela-do-campo; mas iremos tratar como Macela. As flores são amarelo-dourado, as centrais hermafroditas, em número de uma a duas, e as flores marginais são quatro ou cinco (de Lima, 2014).

A planta é geralmente encontrada em pastos e campos agrícolas abandonados. As suas flores secas são utilizadas na medicina caseira. A infusão das inflorescências da macela (Achyrocline satureioides) é popularmente empregada como sedativa, antiinflamatória, antiespasmódica e contra desordens intestinais (Gomes et al., 2019).

O Brasil tem a maior biodiversidade do mundo, cerca de 60.000 espécies vegetais, e mesmo com tanta riqueza vegetal o índice de uso de produtos fitoterápicos pela população brasileira ainda é baixo, sendo utilizadas para pesquisa dos seus compostos bioativos apenas $8 \%$ dessas espécies e 1.110 espécies avaliadas pela sua capacidade medicinal. Nota-se assim, a grande importância de testar a eficácia desses extratos vegetais frente ao combate das bactérias que acometem a cavidade oral (Gadelha et al., 2013); além disso, é interessante conhecer o perfil fitoquímico dessas plantas medicinais a fim de compreender seus possíveis usos clínicos.

O objetivo desse trabalho foi realizar análise microbiológica e fitoquímica, através da análise do teor de flavonoides, fenóis totais e atividade antioxidante, do extrato das folhas de Achyrocline satureioides (Lam.) DC. (Macela).

\section{Metodologia}

\subsection{Preparo do extrato hidroetanólico das folhas de Achyrocline satureioides (Lam.) DC. (Macela)}

Como matéria prima vegetal, foram utilizadas as folhas da Achyrocline satureioides (Lam.) DC. (Macela) colhidas no campo, na cidade de Maria da Fé/ MG, no dia 03 de junho de 2020, no período da tarde, no outono sob as coordenadas geográficas $22^{\circ} 18^{\prime} 50^{\prime \prime} \mathrm{S}$ de latitude e $45^{\circ} 21^{\prime} 47^{\prime \prime} \mathrm{O}$ de longitude.

O preparo do extrato bruto das folhas foi adaptado segundo os estudos de Campos et al. (2016). As folhas da macela foram lavadas e imersas em solução de hipoclorito de sódio a $0,01 \%$ para desinfecção e submetida à secagem prévia até massa constante em temperatura ambiente. A moagem foi realizada utilizando de moinho de facas industrial. Após isso, foram submetidas à maceração hidroetanólica $(70 \%$ v/v), na proporção de 1 parte do pulverizado das folhas em 10 partes de solução extrativa (etanol 70 \%). Após 7 dias de maceração com agitação periódica, o líquido extrativo foi filtrado. O solvente (etanol $70 \% \mathrm{v} / \mathrm{v}$ ) foi retirado por secagem chapa aquecedora em temperatura constante de $45 \pm 2^{\circ} \mathrm{C}$ até que se chegasse a uma massa constante.

\subsection{Análises microbiológicas}

O extrato hidroetanólico das folhas da macela foi adicionado na proporção de $1 \mathrm{~g} / 9 \mathrm{ml}$ de água destilada para a realização da análise microbiológica. Os microrganismos analisados estão dispostos no Quadro 1.

Quadro 1 - Microrganismos utilizados na análise microbiológica.

\begin{tabular}{|l|l|}
\hline \multicolumn{1}{|c|}{ Bactérias } & \multicolumn{1}{|c|}{ Fungos } \\
\hline Estafilococos aureus & Cândida auris \\
\hline Estafilococos mutans & Cândida dubliniensis \\
\hline Estreptococcus pyogenes & Cândida glabrata \\
\hline Escherichia coli & Cândida parapsilosis \\
\hline & Cândica tropicalis \\
\hline
\end{tabular}

Fonte: Autores. 
Foram utilizadas placas de petri estéreis com dois tipos de ágar: o ágar sangue, utilizadas para bactérias, e o ágar Sabouraud Dextrose (ASD - Himedia ${ }^{\circledR}$ ), para as cândidas; ambas foram previamente preparadas por no máximo 7 dias antes da inoculação.

Os microrganismos estavam em meio de cultura em caldo de infusão de cérebro e coração (BHI) antes da sua inoculação, onde se encontrava muito concentrada, sendo assim foram transferidas para tubos com solução salina estéril [ $\mathrm{NaCl}$ 0,85\%, (p/v)] até que se obtivesse turbidez correspondente à escala de McFarland 0,5 (aproximadamente 1x108 UFC/mL) (CLSI, 2003a). Toda a manipulação bacteriana foi realizada em condições assépticas de câmara de fluxo laminar.

O método de difusão em ágar sangue e Sabouraud Dextrose (ASD - Himedia®) foi realizado e ajustado de acordo com Araújo (2011). A atividade microbiológica do extrato foi testada em bactérias e fungos. Como controle positivo para o teste em bactérias foi usada uma pastilha de Ciprofloxacina, um antibiótico, para analisar o crescimento do halo e comparar com o halo do extrato; e, como controle negativo foi utilizado $150 \mu \mathrm{L}$ de água estéril para a comparação. Para as cândidas, o controle de crescimento utilizado foi o antifúngico Cetoconazol para comparar os halos formados nas placas.

Posteriormente, as placas foram então incubadas a $37^{\circ} \mathrm{C}$, em condições aeróbicas e após 24 horas foram medidos com auxílio de paquímetro digital, o diâmetro formado pelo halo de inibição promovido pelos extratos e controles, sendo usado como parâmetro do poder de inibição de cada substância contra o microrganismo testado. O potencial antimicrobiano é avaliado por sua equivalência proporcional ao controle positivo.

\subsection{Perfil fitoquímico}

A metodologia para avaliar o perfil fitoquímico do extrato foi seguida e adaptada de acordo Alves \& Kubota (2013) e Trindade et al. (2018), realizada no Laboratório de Farmacologia e Bioquímica Experimental da Universidade José do Rosário Vellano (UNIFENAS).

\subsubsection{Determinação de compostos fenólicos}

Para a determinação do teor de compostos fenólicos totais dos extratos baseou-se nos métodos de Folin-Ciocalteu por espectrofotometria em $740 \mathrm{~nm}$. O extrato bruto solúvel em água nas concentrações de $100 \mathrm{mg} / \mathrm{ml}, 50 \mathrm{mg} / \mathrm{ml}, 5 \mathrm{mg} / \mathrm{ml}$ e 2,5 $\mathrm{mg} / \mathrm{ml}$ de extrato bruto solúvel de alecrim (EBSA) e extrato bruto solúvel de erva mate (EBSEM). Foi utilizada uma solução de molibidato de sódio (5\%), Carbonato de sódio (0,377M) e Padrão de ácido gálico (PAG) nas concentrações de 100 ug/ ml, $50 \mathrm{ug} / \mathrm{ml}, 10 \mathrm{~m}$ ug/ ml, para construção da curva de calibração.

Foram adicionados 1600 uL de solução de molibidato de sódio (5\%) e 400 uL de amostra (PAG, EBSA e EBSEM) em tubos de ensaio. A solução foi encubada em temperatura ambiente por oito minutos. Após isso, foram adicionados $400 \mathrm{uL}$ da solução de carbonato de sódio $(0,377 \mathrm{M})$ e as amostras encubadas por duas horas, em temperatura ambiente e protegidas de luz. O álcool metílico foi utilizado como branco, sendo utilizados 1000 uL de água destilada. A absorbância (Aa) da fração líquida foi determinada a $740 \mathrm{~nm}$ em espectrofotômetro. Cada solução foi trabalhada de forma triplicada, sendo assim, cada solução possui como resultado três vezes a sua absorbância para que se tenha uma margem de erro e como resultado uma média das três absorbâncias de cada diluição.

\subsubsection{Determinação de flavonoides}

Para determinar o teor de flavonoides totais dos extratos a metodologia foi adaptada utilizando o método de Dowd (Alves \& Kubota, 2013). Os extratos brutos solúveis foram diluídos em água destilada na concentração de 50 ug/ ml, 10 ug/ ml, 1 ug/ ml. Foram utilizadas as soluções de Cloreto de alumínio (10\%) e Acetato de Potássio (1M). 
Em tubos de ensaio foram adicionados $500 \mathrm{uL}$ de amostra, 1,5 mL de etanol, $100 \mathrm{uL}$ de solução de cloreto de alumínio (10\%), 100 uL de solução de acetato de potássio (1M) e 2,8 $\mathrm{mL}$ de água destilada. Para o branco foram adicionados $1,5 \mathrm{~mL}$ de etanol para que haja o balanceamento do espectro, no caso, zerando o espectro, assim conseguimos analisar qual é o índice correto da amostra, 100 uL de solução de cloreto de alumínio (10\%), 100 uL de solução de acetato de potássio (1M) e 2,8 $\mathrm{mL}$ de água destilada. Essas soluções também foram triplicadas. As amostras foram encubadas pelo período de 30 minutos em temperatura ambiente e protegidas de luz. A leitura da absorbância (Aa) da fração líquida foi determinada a $425 \mathrm{~nm}$ em espectrofotômetro.

\subsubsection{Atividade sequestrante de radicais livres}

A metodologia foi adaptada usando o método de Dowd descrita por Alves \& Kubota (2013). Para a realização do ensaio foram preparadas adicionando-se $1 \mathrm{~mL}$ da solução de DPPH $(0,02 \%)$ em $10 \mathrm{~mL}$ de soluções dos extratos que foram diluídas em água destilada nas concentrações de $10 \mathrm{mg} / \mathrm{mL}, 1 \mathrm{mg} / \mathrm{mL}, 0,1 \mathrm{mg} / \mathrm{mL}, 0,5 \mathrm{mg} / \mathrm{mL}, 0,01 \mathrm{mg} / \mathrm{mL}, 0,001 \mathrm{mg} / \mathrm{mL}$ de triplicata e $50 \mathrm{~mL}$ de etanol.

A solução de DPPH possui uma coloração roxa intensa na qual se torna amarelada caso na amostra ocorra a atividade antioxidante (Nunes et al., 2008). Um teste em branco foi realizado adicionando-se $50 \mathrm{~mL}$ de etanol a $10 \mathrm{~mL}$ das concentrações dos extratos.

Como controle negativo foi usada a mistura de $1 \mathrm{~mL}$ da solução de DPPH com $50 \mathrm{~mL}$ de etanol e como controle positivo utilizou-se o $4 \mathrm{~mL}$ das concentrações de BHT (butil-hidroxitolueno) e $1 \mathrm{~mL}$ da solução de DPPH. As amostras foram encubadas pelo período de 30 minutos em temperatura ambiente, protegidos da luz. A absorbância (Aa) da fração líquida foi determinada a $517 \mathrm{~nm}$ em espectrofotômetro.

\section{Resultados e Discussão}

\subsection{Análises microbiológicas}

O extrato etanólico na concentração de 50\% não inativou as cepas de Staphylococcus aureus, Staphylococcus mutans, Streptococcus pyogenes, Escherichia coli, Candida auris, Candida parapsilosis, Candida tropicalis, Candida glabrata, Candida dubliniensis.

O extrato etanólico da Macela obtido apresentava cor verde escuro e com forte odor aromático, como descrito na literatura (Zampieron, 2010). A não inativação das cepas na análise microbiológica pode ter sido devido às diferentes variáveis, como a quantidade de cepa utilizada, proporção, peso, volume do extrato que podem alterar o seu poder antioxidante, anti-inflamatório e antibacterianos presentes nos componentes metabólitos secundários da Macela (Seeling, Grazziotin, 2014).

O estudo de Seeling e Grazziotin (2014) avaliou o extrato aquoso da infusão da Macela de três marcas comerciais diferentes na concentração de $0,5 \%$ e também não encontrou atividade antibacteriana nas cepas de S. aureus, E. faecalis, E. coli e S. choleraesuis, observou somente inibição do controle positivo, o que corrobora com os resultados encontrados em nosso estudo.

\subsection{Perfil fitoquímico}

Os teores encontrados de fenóis totais nas amostras de extratos da folha da Achyrocline satureioides (Lam.) DC. foi de 5,46 \pm 0,07 gEAG/100g de extrato. Segundo Martins (2013) os compostos fenólicos são definidos como substâncias que possuem um anel aromático com um ou mais grupo hidroxila como substituinte. Nos vegetais estes compostos constituem um grupo quimicamente heterogêneo, com aproximadamente 10.000 compostos. 
Dentre estes, alguns são solúveis apenas em solventes orgânicos, enquanto outros como, por exemplo, ácidos carboxílicos e glicosídeos são solúveis em água, além dos grandes polímeros insolúveis (Rockenbach et al., 2008). Os resultados observados demonstram que o extrato bruto das folhas da macela apresentou uma maior quantidade de compostos fenólicos quando comparados com os demais extratos analisados neste estudo.

O teor de flavonoides encontrados nas amostras de Achyrocline Satureioides foi de $883,8 \pm 79 \mathrm{mg}$ EQ/100g de extrato hidroetanólico das folhas de macela.

Os polifenóis possuem grande atividade antioxidante devido a sua capacidade redutora, doando oxigênio e neutralizando os radicais livres, que são responsáveis por muitos problemas sistêmicos, como envelhecimento e as inflamações crônicas. A literatura acredita que as plantas possuem em sua composição grande quantidade de polifenóis devido a própria proteção dos radicais livres, vindas do estresse oxidativo que sofrem (Cezarotto, 2009).

Um estudo sobre os princípios ativos das plantas medicinais, analisou o perfil fitoquímico do extrato etanólico da influorescência da Macela, encontrando na sua composição grande quantidade de flavonoides como a Quercetina, 3Ometilquercentina e Luteolina. Demonstrou ainda, a existência de ácido cafeíco, clorogênico e isoclorogênico (Silva, 2013).

A análise fotoquímica é importante para averiguar a identidade e qualidade da Achyrocline Satureioides (Lam.) DC. (Macela) e diversos estudos estão em comunhão com a afirmação de que as partes aéreas da macela possuem diferentes ácidos fenólicos. Corrêa et al. (2016) identificou compostos de quercitina, luteolina e O-metilquercetina como sendo os principais flanovóides existentes no extrato etanólico de Macela. Além disso, estudaram os efeitos dos compostos encontrados na Achyrocline Satureioides (Lam.) DC. (Macela) e observaram que dependendo do método de extração realizado pode ocorrer uma alteração no resultado fitoquímico.

Alguns autores descrevem que a análise fitoquímica da Macela é rica em polifenóis e terpenos que exercem a atividade antioxidante, antiinflamatória e antimicrobiana da planta. No entanto, deve ser levado em consideração as variações temporais (água, radiação, solo, altitude, fase de desenvolvimento das plantas, etc.) para não alterar a produção e concentração desses metabólitos secundários (Trindade et al., 2018).

Os flavonoides possuem atividades oxidantes que são importantes na proteção celular, evitando o estresse oxidativo e a formação dos radicais livres que podem ser encontrados em algumas patologias como doença de Parkinson, Alzheimer, diabetes, entre outras (Moresco, 2017).

\subsection{Capacidade sequestrante do radical DPPH}

O método sequestrante de radicais livres tem sido utilizado por diversos autores para avaliar a capacidade antioxidante de extratos vegetais. Assim como o método de Folin-Ciocaulteau, o ensaio do DPPH também é baseado em reação de transferência de prótons (Alves et al., 2010; Niki, 2010). Extratos com alto teor de compostos fenólicos, tais como os flavonoides, têm se mostrado propensos para uma boa capacidade sequestrante de radical livres.

O gráfico 1 demonstra a cinética da atividade sequestrante de radical DPPH. A média da capacidade sequestrante do radical DPPH do extrato da macela foi de $52,53 \pm 1,5 \%$, enquanto a média da capacidade sequestrante do radical DPPH do BHT foi de $94,78 \pm 0,09 \%$. Possivelmente este resultado está relacionado a alta quantidade de flavonoides e fenóis observados no extrato da macela. Apesar da interessante capacidade sequestrante do radical DPPH, o extrato da macela não apresentou uma atividade sequestrante de radical DPPH similar ao padrão sintético BHT.

Os flavonoides são uma classe de metabólitos especiais com hidroxilas fenólicas capaz de neutralizar radicais livres e continuar estável por ressonância por suas duplas ligações alternadas. 
Gráfico 1 - Capacidade sequestrante do radical DPPH.

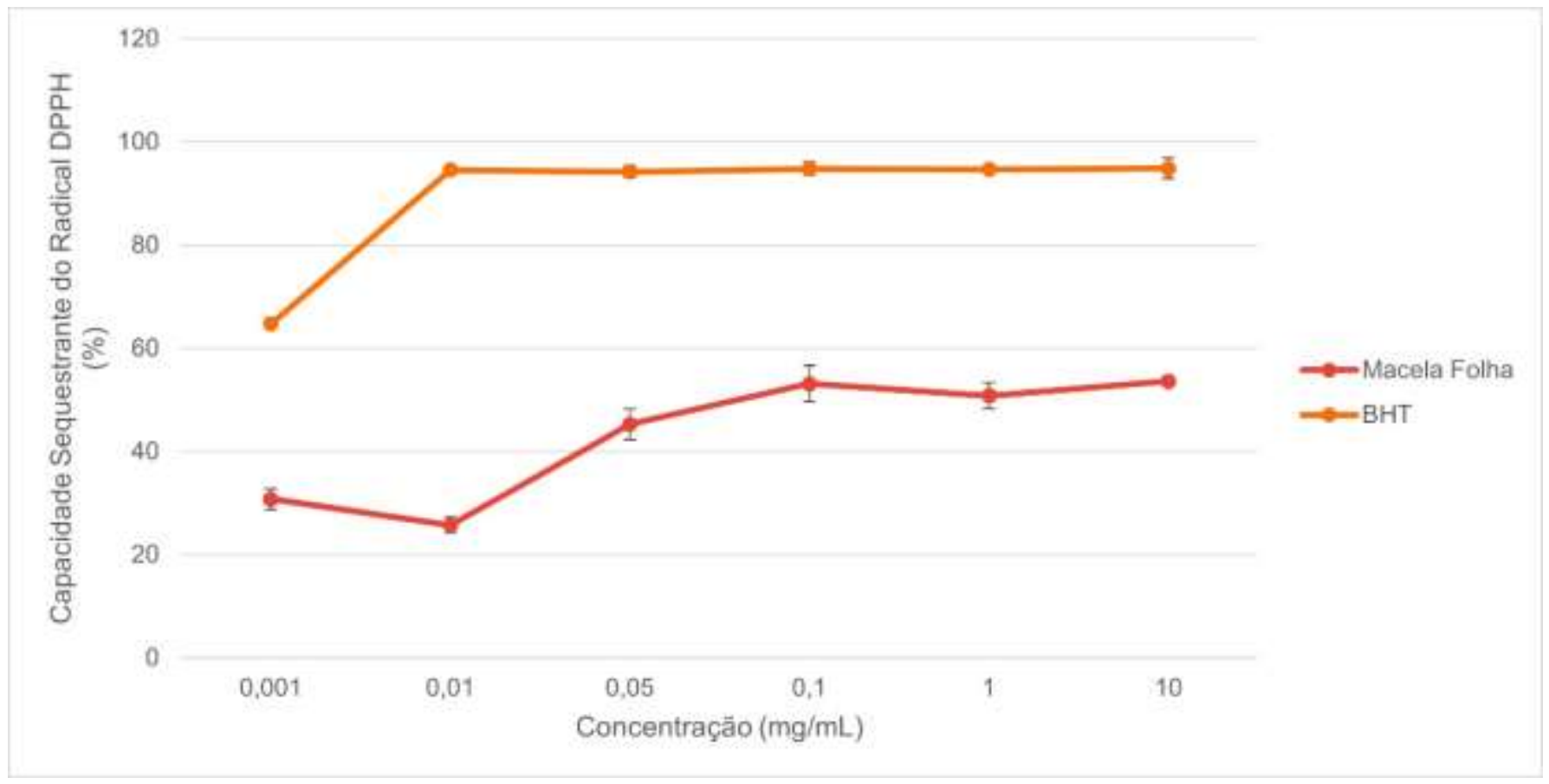

Fonte: Autores.

Os resultados mostraram que o extrato bruto das folhas da macela, apresenta um alto potencial antioxidante. Entretanto, estudos em modelos animais será necessário para avaliar os efeitos antioxidantes do extrato in vivo.

Zampieron (2009) analisou e comparou a atividade antioxidante do extrato de Achyrocline alata (Kunth.) DC. em relação ao extrato de Achyrocline satureioides (Lam.) DC. com o radical DPPH, que tem sido amplamente usado para observação e monitoramento por autografia e quantificação do potencial de captação de radicais livres de extratos, frações e substâncias isoladas de plantas medicinais. Após a comparação foi possível constatar que a A. satureioides apresentou-se ligeiramente mais eficaz quando analisado lado aos da espécie sucedânea (A. alata), especialmente quando comparada em sua concentração mais alta. Apesar das duas plantas apresentarem altos teores de flavonoides que são reconhecidos pela sua atividade antioxidante não se demonstraram tão eficazes quanto a substancias reconhecidamente ativas.

Santos, David e David (2013) em um estudo experimental utilizou os extratos metanólicos e hexânicos da própolis para o teste de atividade antioxidante in vitro em que nos seus resultados não apresentaram atividade oxidante superior a $20 \%$. O extrato hexânico apresentou IC50 = 1,192 x 10-3 $\mu \mathrm{g}$ mL-1 enquanto que o extrato metanólico apresentou IC50=5,26 x 10-2 $\mu \mathrm{g}$ mL-1. O IC50. A baixa oxidação pode ser atribuída pelo baixo teor de compostos fenólicos na própolis, visto que a fração primária dos extratos não levou a identificação ou isolamento de compostos de natureza fenólica e sim de compostos com natureza mais apolar. De acordo com esse estudo, a quantidade de flavonoides encontrado no nosso extrato bruto da Macela é superior quando comparado ao encontrado no extrato de propólis.

Rodrigues, da Silva e Macedo (2017) com o extrato etanólico da folha da Morinda Citrifolia Linn julgaram a atividade antioxidante pelo método de DPPH. Através da análise de alguns autores que estabeleceram um padrão de comparação utilizando ácido gálico com o uso extrato aquoso do fruto de noni e o extrato etanólico da folha em concentrações baixas, através da metodologia da captura de radicais livres DPPH, como resultado obtiveram cerca de $85 \%$ da captura de radicais sob concentrações de $0,1 \mathrm{~g} / \mathrm{L}$. Também foram realizados testes antioxidantes com reagente DPPH utilizando extrato etanólico da folha de noni (Morinda citrifolia Linn) sob altas e baixas concentrações e identificou eficácia antioxidante do extrato, devido a alteração na coloração. Relatam também que um bom antioxidante é caracterizado pela capacidade de 
capturar radicais livres mesmo em baixas concentrações. Dessa forma, de acordo com os autores, para que extrato estudado seja considerado um bom antioxidante, esse deve ser capaz de capturar radicais livres mesmo em baixas concentrações.

\section{Conclusão}

O extrato da folha da Macela quando analisado por espectrofotometria apresentou altos teores de flavonoides e de compostos fenólicos totais em todas as amostras. No entanto, mesmo com essa grande quantidade de metabólitos secundários, quando comparado ao antioxidante sintético o extrato não apresentou uma capacidade correspondente, sendo necessários mais estudos dos seus efeitos.

A análise microbiológica mostrou que o extrato etanólico não foi capaz de inibir a atividade e o crescimento microbiano de nenhum dos patógenos analisados. Sendo assim, devem ser realizados mais estudos acerca da atividade antimicrobiana da Macela, pois como o extrato puro é rico em compostos fenólicos totais e flavonoides, espera-se que ele tenha a capacidade de inibir a atividade de algum patógeno.

\section{Referências}

Alves, C. Q., David, J. M., David, J. P., Bahia, M. V., \& Aguiar, R. M. (2010). Métodos para determinação de atividade antioxidante in vitro em substratos orgânicos. Química Nova, 33(10), 2202-2210. https://doi.org/10.1590/S0100-40422010001000033

Alves, E., \& Kubota, E. H. (2013). Conteúdo de fenólicos, flavonoides totais e atividade antioxidante de amostras de própolis comerciais. Revista de Ciências Farmacêuticas Básica e Aplicada, 34(1). http://rcfba.fcfar.unesp.br/index.php/ojs/article/view/233

Araujo, Y. L. F. M. D., Lima, Á. S., Orellana, S. C., \& Araujo, E. D. (2011). Comparação entre duas técnicas utilizadas no teste de sensibilidade antibacteriana do extrato hidroalcoólico de própolis vermelha. Scientia Plena, 7(4). https://www.arca.fiocruz.br/handle/icict/8664

Campos, F. L., Valente, P., Ethur, E. M., \& Avancini, C. (2016). AM. Atividade desinfetante do extrato hidroalcoólico bruto de Achyrocline satureioides (Asteraceae) sobre Candida spp. isoladas em situações-problema de mastite bovina. Acta Veterinaria Brasilica, 10(4), 327-333. https://pdfs.semanticscholar.org/a250/c44f1b20e19ad915f82a41ed7450ec2dd3de.pdf

Carvalho, A. C. B., \& Geron, V. L. M. G. (2018). Administração de fitoterapias em crianças e o uso concomitante de medicamentos convencionais. Trabalho de conclusão de curso (TCC) em Farmácia, Faculdade de Educação e Meio Ambiente (FAEMA), Ariquemes - RO, Brasil. http://repositorio.faema.edu.br:8000/jspui/handle/123456789/2343

Cezarotto, V. S. (2009). Influência da sazonalidade nos constituintes químicos, atividade antimicrobiana e antioxidante das partes aéreas de Baccharis articulata (Lam) Pers e Achyrocline satureioides (Lam.) DC. Dissetação de Mestrado em Química Analítica, Universidade Federal de Santa Maria (UFSM), Santa Maria - RS, Brasil. https://repositorio.ufsm.br/bitstream/handle/1/10453/CEZAROTTO,\%20VERCIANE\%20SCHNEIDER.pdf

Corrêa, B. J. M., Marchionatti Avancini, C. A., Spaniol, B., \& Ros Petrovick, P. (2016). Actividad desinfectante anti-Staphylococcus aureus meticilina resistentes y compuestos flavonoides en Achyrocline satureioides Lam (macela). Revista Cubana de Plantas Medicinales, 21(4), 1-12. https://www.medigraphic.com/cgi-bin/new/resumen.cgi?IDARTICULO=75683

de Lima, S. N. (2014). Utilização de extrato de marcela (achyrocline satureioides) como antioxidante natural em salsichas de carne mecanicamente separada de tilápia (Oreochromis niloticus). Dissertação de Mestrado em Ciência e Tecnologia de Alimentos, Instituto Federal de Educação, Ciência e Tecnologia do Triângulo Mineiro (IFTM), Uberaba - MG, Brasil. http://serv-bib.fcfar.unesp.br/seer/index.php/alimentos/article/viewArticle/636

Gadelha, C. S., Junior, V. M. P., Bezerra, K. K. S., Pereira, B. B. M., \& Maracajá, P. B. (2013). Estudo bibliográfico sobre o uso das plantas medicinais e fitoterápicos no Brasil. Revista Verde de Agroecologia e Desenvolvimento Sustentável,8(5), 208-212. https://dialnet.unirioja.es/servlet/articulo?codigo=7404604

Gomes, D. C., Coriolano, M. C., Holanda, V. N., \& dos Santos Correia, M. T. (2019). Utilização de Achyrocline satureioides (Lam) DC na medicina popular e aplicações biológigas relatadas. Revista Interfaces: Saúde, Humanas e Tecnologia, 6(17), 173-177. http://interfaces.leaosampaio.edu.br/index.php/revistainterfaces/article/view/620/pdf

Moresco, K. S. (2017). Efeitos terapêuticos de Achyrocline satureioides (Lam.): estudos in vivo e in vitro. Dissertação de Doutorado em Ciências Biológicas: Bioquímica, Universidade Federal do Rio Grande do Sul (UFRS), Porto Alegre - RS, Brasil. https://www.lume.ufrgs.br/handle/10183/175026

Niki, E. (2010). Assessment of antioxidant capacity in vitro and in vivo. Free Radical Biology and medicine, 49(4), 503-515. 10.1016 / j.freeradbiomed. https://doi.org 2010.04.016

Nunes, X. P., Mesquita, R. F., Silva, D. A., Lira, D. P., Costa, V. C., Silva, M. V., \& Agra, M. D. F. (2008). Constituintes químicos, avaliação das atividades citotóxica e antioxidante de Mimosa paraibana Barneby (Mimosaceae). Revista Brasileira de Farmacognosia, 18, 718-723. https://doi.org/10.1590/S0102$695 \times 2008000500015$

Rockenbach, I. I., Silva, G. L. D., Rodrigues, E., Kuskoski, E. M., \& Fett, R. (2008). Influência do solvente no conteúdo total de polifenóis, antocianinas e atividade antioxidante de extratos de bagaço de uva (Vitis vinifera) variedades Tannat e Ancelota. Food Science and Technology, 28, 238-244. https://doi.org/10.1590/S0101-20612008000500036 
Research, Society and Development, v. 10, n. 4, e51510414428, 2021

(CC BY 4.0) | ISSN 2525-3409 | DOI: http://dx.doi.org/10.33448/rsd-v10i4.14428

Rodrigues, L. S., da Silva, A. R. A., \& Macêdo, A. A. M. (2017). Noni (Morinda citrifolia Linn.): Determinação Fitoquímica e Potencial Antioxidante pelo Método DPPH. Conexões-Ciência e Tecnologia, 11(4), 47-54. https://doi.org/10.21439/conexoes.v11i4.921

Santos, D. C. D., David, J. M., \& David, J. P. (2017). Composição química, atividade citotóxica e antioxidante de um tipo de própolis da Bahia. Química Nova, 40(2), 171-175. https://doi.org/10.21577/0100-4042.20160174

Seelig, A., \& Grazziotin, N. (2014). Avaliação da atividade antibacteriana de extratos aquosos de influorescências de Achyroclyne satureioides de três marcas comerciais diferentes. Perspectiva, 38(141), 89-98. https://www.uricer.edu.br/site/pdfs/perspectiva/141_394.pdf

Silva, I. (2013). Estudo fitoquímico e etnobotânico das plantas medicinais mais comercializadas nas feiras livres de alguns municípios do Curimataú paraibano e do Trairí potiguar. Trabalho de Conclusão de Curso (TCC) em Química licenciatura, Universidade Federal de Campina Grande (UFCG), Cuité - PB, Brasil. http://dspace.sti.ufcg.edu.br:8080/jspui/handle/riufcg/10714

Trindade, G., Ribeiro, T. S., Peçanha, F. F., Menezes, A. P. S., Maldaner, G., \& mariño, p. A. (2018). Doseamento De Polifenóis Em Diferentes Extratos Das Inflorencências De Achyrocline Satureioides. Anais do Salão Internacional de Ensino, Pesquisa e Extensão, 10(2), https://periodicos.unipampa.edu.br/index.php/SIEPE/article/view/100225

Zampieron, R. G. (2010). Estudo químico e potencial antioxidante de espécies vegetais utilizadas na medicina popular de Mato Grosso do Sul-Achyrocline alata (kunth) dc. e Achyrocline satureioides (lam.) Dc.-asteraceae. Dissertação de Doutourado em Ciências da Saúde, Universidade de Brasília, Brasília - DF, Brasil. https://repositorio.unb.br/handle/10482/8193 